\title{
Modelling the biomechanical behaviour of growing trees at the forest stand scale. Part I: Development of an Incremental Transfer Matrix Method and application to simplified tree structures
}

\author{
Philippe ANCELIN ${ }^{\mathrm{a}, \mathrm{b}}$, Thierry FOURCAUD ${ }^{\mathrm{a}, \mathrm{b} *}$, Patrick LAC $^{\mathrm{a}}$ \\ a Laboratoire de Rhéologie du Bois de Bordeaux, UMR CNRS/INRA/Université Bordeaux I, Domaine de l'hermitage, 69 route d'Arcachon, \\ 33612 Cestas Cedex, France \\ b Programme Modélisation des Plantes, CIRAD-AMIS - AMAP - TA40/PS2, boulevard de la Lironde, 34398 Montpellier, France
}

(Received 18 July 2002; accepted 23 April 2003)

\begin{abstract}
Stem straightness defects are often associated with heterogeneities in wood structure in relation to tree tropisms. This paper presents a numerical model which is dedicated to simulate the biomechanical behaviour of growing trees. A simplified description of tree structure, separating trunk and crown, has been used in order to perform future calculations at the stand level. The model is based on the Transfer Matrix Method, which was adjusted under an incremental form to compute the evolution of trunk biomechanics during growth. Deflections due to selfweight distribution and straightening up reactions, which are associated with maturation strains of reaction wood cells, were considered. This model has been implemented in the CAPSIS software. Numerical results were compared to those obtained by the software AMAPpara, which is more applicable to the whole tree architecture level. Limits of the simplified description, which will be useful for studies at stand level, are discussed.
\end{abstract}

biomechanics / negative-gravitropic response / reaction wood / stem shape / growth stresses

Résumé - Modélisation du comportement biomécanique d'arbres en croissance à l'échelle du peuplement forestier. Partie I : développement d'une Méthode Incrémentale des Matrices de Transfert et application au cas d'arbres simplifiés. Les défauts de rectitude des tiges sont souvent associés à des hétérogénéités structurelles du bois via des phénomènes de tropismes. Cet article présente un modèle numérique de simulation du comportement biomécanique des arbres en croissance. Une description simplifiée de la structure, considérant séparément le tronc et le houppier, a été adoptée afin de permettre des calculs futurs à l'échelle du peuplement forestier. Le modèle numérique est basé sur une formulation incrémentale de la Méthode des Matrices de Transfert permettant de tenir compte de l'évolution de l'état mécanique du tronc tout au long de la croissance de l'arbre. Le modèle prend en compte les déformations dues au poids propre de la structure, mais aussi les phénomènes de redressement associés aux déformations de maturation du bois de réaction. Ce modèle a été implanté dans le logiciel CAPSIS. Les résultats numériques ont été comparés à ceux obtenus en utilisant le logiciel AMAPpara. Ce dernier utilise un modèle biomécanique reposant sur une description détaillée de l'architecture de l'arbre. Les limites d'une description simplifiée de la structure, qui sera utile pour des calculs à l'échelle du peuplement forestier, sont discutées.

biomécanique / réponse gravitropique négative / bois de réaction / forme des troncs / contraintes de croissance

\section{INTRODUCTION}

Stem shape defects are closely associated with tree biomechanical behaviour. These defects are often linked with pith eccentricity and reaction wood formation. They have a huge impact on timber quality and hence reduce economic viability. In a recent synthesis, Fourcaud [18] discusses these issues with regard to Maritime pine (Pinus pinaster Ait.), for which trunk straightness constitutes one of the main quality criteria enabling stand production to be estimated. The immediate deformations $[11,37,45]$, which are often observed during wood harvesting and/or wood transformation, are attributed to high mechanical stresses, which are called growth stresses. These stresses accumulate as a result of the history of both quasi-static loadings, e.g. self-weight and prevailing wind, and biomechanical processes occurring near the cambium, i.e. changing of cell volume during the maturation process [5, 24, 26, 37, 43]. Several studies have been carried out on the progressive accumulation of such stresses in trees during growth [3, 21, 22, 24, 26]. These studies highlighted the significant difference between the stresses estimated considering the tree is growing and those predicted by classical methods of calculating strength of materials in non-growing structures.

\footnotetext{
* Corresponding author: fourcaud@lrbb3.pierroton.inra.fr
} 
During the last few decades, simulation tools have been developed in order to analyse tree biomechanical behaviour at various spatial scales. In particular, Fourcaud and Lac [19] have developed a finite element biomechanical model which was implemented in the software AMAPpara at the tree level, and included the whole branching system [34, 35]. This mechanical module, which is called AMAPméca, allows the relationship between tree architecture and biomechanical behaviour to be analysed [20]. However, this software is not adapted to calculate the biomechanical behaviour of a large number of growing trees due to the numerical complexity which is inherent to such detailed architectural models.

A number of tree growth models are concerned with investigating wood production and wood quality at the stand level. Some models consider the position of trees in the stand, in order to take into account the competition effects or the influence of environmental parameters $[4,12,17,33,39]$. Due to the large number of individuals to be considered, crown structure is often described as a more or less simplified geometrical form, neglecting the topological organization of branches $[8,9,13,36]$. Similarly, at the stand level, modelling of biomechanical behaviour does not necessarily require detailed description of tree structure as is the case at the individual scale [2]. This modelling has to be undertaken taking care to obtain a correct compromise between the computation cost, which is related to the number of trees in the stand, and the model accuracy. For this reason, this paper presents tree mechanical calculations only concerned with the single stem. Crown description was reduced to a volume and its associated biomass. Suppressing the important quantity of information relative to the branching system allowed applications to be performed for a large number of trees. Simplified description of the crown biomass distribution can be adequate for specific mechanical calculations, especially when the tree can be considered as a non-growing structure at a given time [23, 32, 41]. Nevertheless, instantaneous global crown shape cannot provide sufficient information as the tree growth has to be taken into consideration in biomechanical models. Such models are based on stepwise calculations and require the distribution of the increment of biomass, which is built at each cycle of growth [7, 19, 22].

An Incremental Transfer Matrix Method (ITMM) of straight beams was developed in order to perform numerical analysis of growing stem biomechanical behaviour [2]. The Transfer Matrix Method was already used so as to analyse the static shape and stresses in tree shoots/trunks and branches [6, 2831 ]. The particularity of our model is that the progressive building of the structure due to growth necessitated the equilibrium to be formulated under an incremental form. Self-weight increment and growth stresses were taken into account at each cycle of growth for the biomechanical analysis of a tree.

The biomechanical model was implemented under the form of a stepwise procedure in the software CAPSIS (ComputerAided Projection of Strategies In Sylviculture, ${ }^{\circ}$ INRA) [10, 16]. This software is a common computer platform which is dedicated to the development of stand growth models. First calculations were performed using a Maritime pine tree growth model which was issued from Lemoine's stand growth model [27] and implemented in CAPSIS (Dreyfus, INRA Avignon, unpublished work). Some simple functions were considered to describe the location of biomass increment in the crown at each

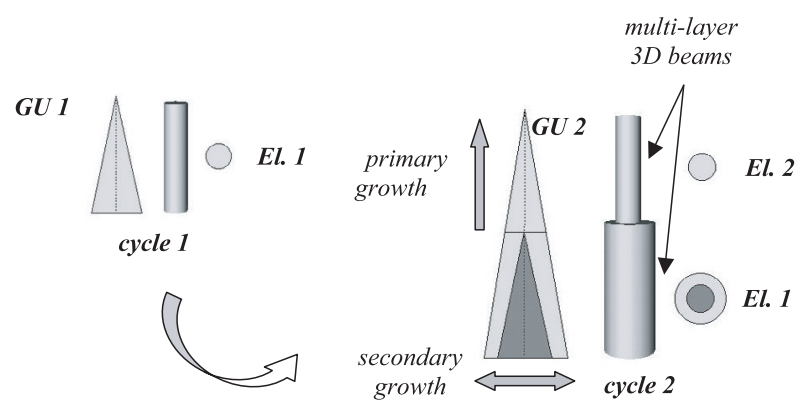

Figure 1. Description and discretization of the stem structure. At each cycle of growth, a new vegetative element is built at the stem tip due to the primary growth. A new layer of wood is formed at the stem periphery due to secondary growth. The tapered trunk is approximated by a series of multi-layer 3D straight beam elements. Primary growth necessitates adding a new element at the top extremity of the slender structure. Secondary growth is taken into account by adding a new external layer to the existing elements.

cycle of growth. The associated self-weight distribution was applied on the simulated tree for the mechanical calculations. Incremental displacements and growth stresses resulting from the calculation were compared with AMAPméca results. Sensitivity to the mode of application of crown weight increments is then discussed.

\section{MATERIALS AND METHODS}

\subsection{Mechanical model for analysis of growing tree stems}

\subsubsection{Growth and time discretization}

The cyclic aspect of tree growth necessitates using time discretization. The time step which has been considered here corresponds to a cycle of growth, i.e. the time it takes to create a new growth unit $(G U)$ [25]. Let ${ }^{n-1} C$ denote the configuration of the deformed stem at the end of the $n-1$ th growth cycle. The reference configuration ${ }^{n} \hat{C}$ at the beginning of cycle $n$ is defined by adding to ${ }^{n-1} C$ a new $G U$ (primary growth) and new wood rings (secondary growth).

Deflection of the structure is assumed to be small during each step of calculation, i.e. configurations ${ }^{n} \hat{C}$ and ${ }^{n} C$ are supposed to be very close together. Consequently, growing tree analysis is performed as a succession of linear problems [2]. The structure geometry is updated at each step of calculation allowing new $G U s$ to be created on a deformed configuration of the stem.

\subsubsection{Description of the trunk internal structure}

Computation time and memory requirements can be very high depending on the number of trees to be analysed. Studies at the forest stand scale necessitate restricting biomechanical calculation to the trunk only. The geometrical discretization of the stem is similar to that given by Fourcaud et al. [20]. The stem is described as an assembly of multi-layer 3D straight beam elements which allow stem taper to be taken into account (Fig. 1). Each mid-height beam radius is calculated using a stem taper equation depending on tree species. Models of stem profile and internal structure such the one developed by Courbet and Houllier [14] can be used to inform the mechanical 
description. Bernoulli's model is used for each beam (cf. Appendix). The multi-layer elements allow the mechanical properties of wood to be defined ring by ring in each $G U$. Cell maturation can be also taken into account in the peripheral growth rings. It is assumed that beam layers are concentric and beam cross-sections are circular.

In ${ }^{n} \hat{C}$, the cross-section of an element which appeared at cycle $d$ is defined by layers which are numbered from $d$ to $n$. External radius, cross-section area, moment of inertia and elastic constants of layer $c$ $(d \leq c \leq n)$ are noted $R_{c}(\mathrm{~m}), A_{c}\left(\mathrm{~m}^{2}\right), I_{c}\left(\mathrm{~m}^{4}\right), E_{c}(\mathrm{~Pa})$ and $v_{c}$ (dimensionless) respectively. For each mode of deformation, i.e., tension, flexion and torsion, element stiffness is given by:

$$
\left\{\begin{array}{c}
n(E . A)=\sum_{c=d}^{n} E_{c} \cdot A_{c} \quad n(E . I)=\sum_{c=d}^{n} E_{c} \cdot I_{c} \\
{ }^{n}(G . J)=\sum_{c=d}^{n}\left(\frac{E_{c} \cdot I_{c}}{1+v_{c}}\right) \text { with } A_{c}=\pi \cdot\left(R_{c}^{2}-R_{c-1}^{2}\right) ; I_{c}=\pi \cdot\left(R_{c}^{4}-R_{c-1}^{4}\right) / 4 .
\end{array}\right.
$$

\subsubsection{Incremental transfer relation for one cycle of growth}

At cycle $n$, applied load on any beam element of ${ }^{n} \hat{C}$ corresponds to its self-weight increment, i.e. the weight of its peripheral ring $n$. This self loading is expressed as the following components of uniformly distributed load increments $\left(\mathrm{N} \cdot \mathrm{m}^{-1}\right)$ :

$$
\Delta^{n} d_{x}=\rho_{n} \cdot A_{n} \cdot g \cdot{ }^{n} Z_{x} ; \quad \Delta^{n} d_{y}=\rho_{n} \cdot A_{n} \cdot g \cdot{ }^{n} Z_{y} ; \quad \Delta^{n} d_{z}=\rho_{n} \cdot A_{n} \cdot g \cdot{ }^{n} Z_{z} \text {, }
$$

where $\rho_{n}$ is the wood density $\left(\mathrm{kg} \cdot \mathrm{m}^{-3}\right)$ of the external layer, $g$ is the acceleration of gravity $\left(\mathrm{m} \cdot \mathrm{s}^{-2}\right)$ and ${ }^{n} Z_{x},{ }^{n} Z_{y},{ }^{n} Z_{z}$ (dimensionless) are the direction cosines of the vertical $\vec{Z}$ with respect to local axes $\vec{x}, \vec{y}$, $\vec{z}$ of the beam in ${ }^{n} \hat{C}$. State vector of distributed loads $\Delta^{n} D$ is defined by expression (A.5) according to relations (1) and (2). Incremental state vector at the origin and the extremity of the beam are denoted by $\Delta^{n} S_{O}$ and $\Delta^{n} S_{E}$ respectively, according to the definition (A.3). These vectors contain the displacements from ${ }^{n} \hat{C}$ to ${ }^{n} C$ and the internal force increments. If only self-weight increment of the beam is considered, the incremental transfer relation (A.4) is given by:

$$
\Delta^{n} S_{E}={ }^{n} T \cdot \Delta^{n} S_{O}+\Delta^{n} D,
$$

where ${ }^{n} G$ is the transfer matrix defined by expression (A.5) according to the beam characteristics in ${ }^{n} \hat{C}$ given by relations (1). Vector $\Delta^{n} D$ allows consideration of any extra distributed loading to be applied, e.g. wind forces.

\subsection{Including maturation strains in stem biomechanics}

Modelling biomechanical behaviour of trees requires not only translating the effects of accumulating the biomass progressively, but also taking into account intrinsic biological growth phenomena. Numerous works [3, 5, 21, 24, 26, 37, 43] have shown that non released maturation strains $(M S)$ of newly formed cells develop a high level of mechanical stresses in the inner stem. Furthermore, differences in $M S$ between normal and reaction wood generate internal displacements which are involved in the trees negative-gravitropic reaction [44]. The ensemble of mechanical stresses which are due to both $M S$ and tree self-weight are commonly called growth stresses.

It is shown below how the incremental transfer relation (3) should be completed in order to consider the biomechanical effect of cell maturation phenomena at the trunk level.

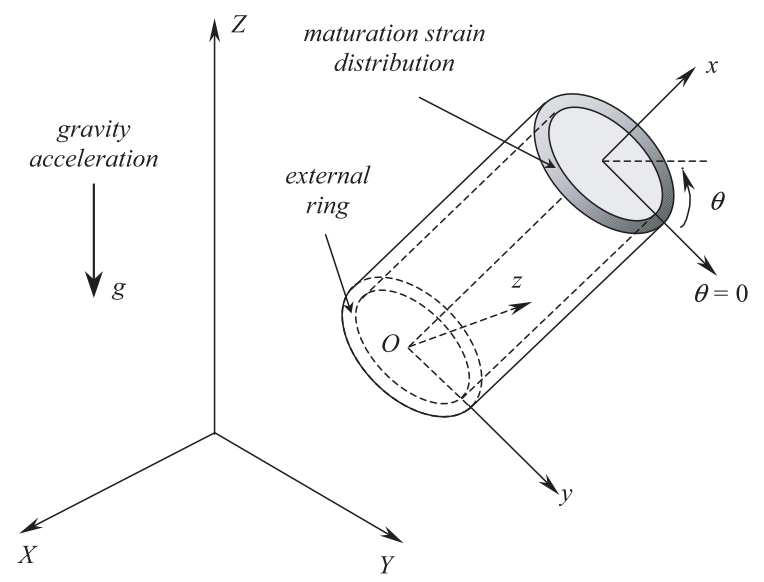

Figure 2. Distribution of maturation strains in the external ring of a trunk segment. At the current cycle of growth, local referential axes of the corresponding beam are chosen so that the $x y$ plane corresponds to the plane of straightening up. Maturation Strains are symmetric about this plane.

\subsubsection{Modelling maturation strains}

Orthogonal local coordinate axes $(x, y, z)$ were associated to each beam element of the stem mesh, in such a way that $\vec{x}$ corresponds to the longitudinal beam axis and $x y$ defines the straightening up local plane (Fig. 2). Local straightening up movement of stem segments was modelled using the simple sinusoidal hoop distribution of $M S$ which was previously proposed by Fourcaud et al. [20]. This model is given at cycle $n$ according to the mentioned local system axis as:

$$
\left\{\begin{array}{l}
{ }^{n} \mu={ }^{n} a+\frac{{ }^{n} \zeta}{2}\left({ }^{n} b-{ }^{n} a\right)(1+\cos (\theta-\psi)) \\
\text { with } \psi=0 \text { if }{ }^{n} b \geq 0 \text { and } \psi=\pi \text { if }{ }^{n} b<0,
\end{array}\right.
$$

where $\theta \in[0,2 \pi]$ is the hoop variable given with respect to $\vec{y}$ axis (Fig. 2). ${ }^{n} a$ and ${ }^{n} b$ define the extreme values of $M S$, for normal wood and reaction wood respectively. With regard to the negative-gravitropism of coniferous trees, longitudinal elongation of compression wood cells is represented by positive values of ${ }^{n} b$ reached at the lower part of the beam, i.e. at $\psi=0$ [37]. However, tension wood shrinkage is defined by negative values of ${ }^{n} b$ reached at $\psi=\pi$ for broadleaf trees. ${ }^{n} a$ and ${ }^{n} b$ can be estimated measuring the longitudinal residual maturation strains (LRMS) on living trees using different techniques [45]. $\zeta_{n}$ is a parameter defining the strategy of straightening up. Basically $\varsigma_{n}=1$ if reaction, $\varsigma_{n}=0$ else, but intermediate values could be used in order to modulate the process.

\subsubsection{Incremental state vector due to maturation strains}

At each cycle of growth, $M S$ of the new cells cannot be released, as the cells are attached to the older stiffened part of the stem. Therefore, axial strain and stress increments of maturation in the whole cross-section are induced. These increments should be noted with an exponent (mat) which is not specified in the following relations in order to keep formulae simple. In the peripheral layer, where the $M S$ occur, the axial strain increment $\left(\Delta^{n} \varepsilon_{x x}\right)$ can be split into elastic axial strain increment $\left(\Delta^{n} \varepsilon_{x x}^{e l}\right)$ and axial $M S\left({ }^{n} \mu\right)$. Generalisation at any point $M$ of ${ }^{n} \hat{C}$ is given by:

$$
\Delta^{n} \varepsilon_{x x}(M)=\Delta^{n} \varepsilon_{x x}^{e l}(M)+{ }^{n} \mu \cdot \delta_{n}(M),
$$

where $\delta_{n}(M)=1$ if $M$ belongs to the external ring $n$ and $\delta_{n}(M)=0$ otherwise. 
The symmetry assumption of $M S$ distribution, with respect to the $x y$ plane, allows the maturation effects to be restricted to the superposition of generalised strain increments of longitudinal tension $\left(\Delta^{n} \varepsilon\right)$ and bending around the $\vec{z}$ axis $\left(\Delta^{n} K_{z}\right)$. Consequently, the total axial strain increment at point $M(x, y, z)$ can be written under the following form:

$$
\Delta^{n} \varepsilon_{x x}(M)=\Delta^{n} \varepsilon-y \cdot \Delta^{n} K_{z} .
$$

Denoting $E(M)$ the longitudinal Young's modulus at point $M(\mathrm{~Pa})$, the axial stress increment $(\mathrm{Pa})$ at point $M$ is given by:

$$
\Delta^{n} \sigma_{x x}(M)=E(M) \cdot \Delta^{n} \varepsilon_{x x}^{e l}(M)=E(M) \cdot\left(\Delta^{n} \varepsilon-y \cdot \Delta^{n} K_{z}-{ }^{n} \mu \cdot \delta_{n}(M)\right)
$$

This axial stress field is self balanced in any beam cross-section area ${ }^{n} A$, i.e., there are no internal forces due to the maturation [2]. It follows:

$$
\int_{n_{A}} \Delta^{n} \sigma_{x x}(M) \cdot d A=0 \text { and } \int_{n_{A}} y \cdot \Delta^{n} \sigma_{x x}(M) \cdot d A=0 .
$$

Generalised tensile and bending strain increments due to the maturation are deduced by substituting from relation (5) the longitudinal stress increment in (6). The orthogonal local coordinate axes $(x, y, z)$ corresponding to inertia principal axes of the beam, it becomes:

$\Delta^{n} \mathcal{E}=\frac{E_{n}}{{ }^{n}(E . A)} \int_{A_{n}}{ }^{n} \mu . d A ; \quad \Delta^{n} K_{z}=\frac{-E_{n}}{{ }^{n}(E . I)} \int_{A_{n}} y \cdot{ }^{n} \mu . d A$,

where $A_{n}$ is the cross section area of the peripheral ring $n$.

Using the $M S$ model (4) in integral equations (7), generalised strain increments due to maturation can be expressed as:

$$
\left\{\begin{array}{l}
\Delta^{n} \mathcal{E}=\frac{E_{n} \cdot A_{n}}{{ }^{n}(E \cdot A)}\left({ }^{n} a+\frac{{ }^{n} \varsigma}{2}\left({ }^{n} b-{ }^{n} a\right)\right) \\
\Delta^{n} K_{z}=-\frac{\pi \cdot{ }^{n} \varsigma \cdot E_{n}}{6 \cdot{ }^{n}(E \cdot I)}\left({ }^{n} b-{ }^{n} a\right)\left(R_{n}^{3}-R_{n-1}^{3}\right) \cos \psi .
\end{array}\right.
$$

By definition, the incremental state vector due to maturation contains six displacement components and six internal force increments. The latter are denoted as zero as maturation does not induce internal forces. Generalised displacement increments are obtained by integrating strain compatibility equations of the Bernoulli's model. We obtain:

$$
\Delta^{n} u=\Delta^{n} \mathcal{E} \cdot x ; \quad \Delta^{n} v=\Delta^{n} K_{z} \cdot \frac{x^{2}}{2} ; \quad \Delta^{n} \omega_{z}=\Delta^{n} K_{z} \cdot x .
$$

Finally, incremental state vector due to maturation in ${ }^{n} \hat{C}$ is given for a beam of length $L$ by:

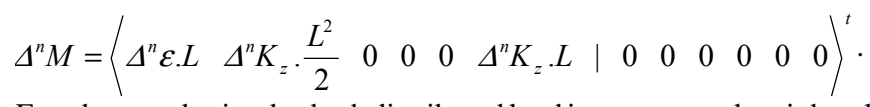
For a beam submitted to both distributed load increment and peripheral maturation strains, the incremental transfer relation (3) takes the following form:

$$
\Delta^{n} S_{E}={ }^{n} T \cdot \Delta^{n} S_{O}+\Delta^{n} D+\Delta^{n} M .
$$

\subsection{Stages of the Incremental Transfer Matrix Method}

In ${ }^{n} \hat{C}$, tree trunk shape is discretized by $n$ beam elements of length $L_{i}(i=1 \ldots n)(\mathrm{m})$. These elements are connected together by structural nodes numbered along the stem from the base to the top $(i=1 \ldots n+1)$. Convention states that element $i-1$ is on the left and element $i$ is on the right of node $i$. The ITMM uses the state vectors which are

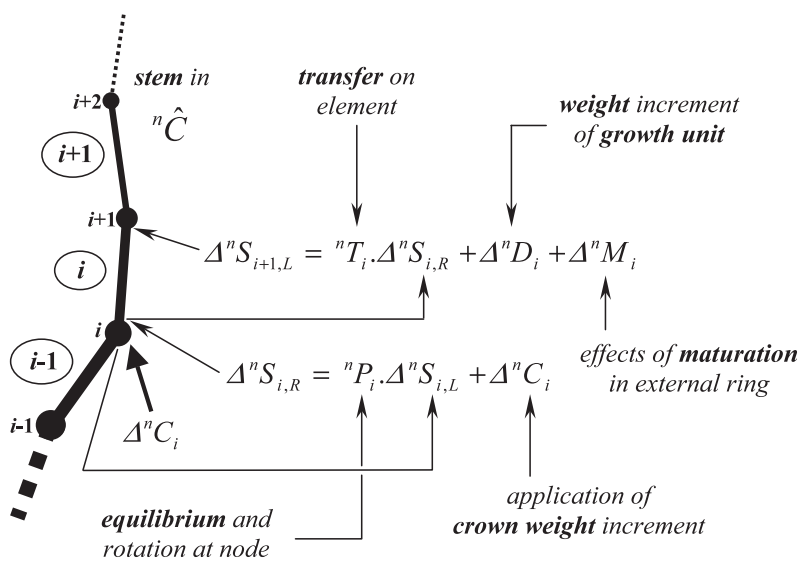

Figure 3. Functional scheme of the Incremental Transfer Matrix Method (ITMM) applied on a growing tree trunk. The stem is discretized with beam elements which are connected to each other by nodes. The ITMM consists of determining the state vectors tracing the structure node by node. Considering element $i$, state vector of the beam origin (node $i$ ) is determined using the equilibrium equation with the previous adjacent element $i-1$. State vector of the extremity node $i+1$ is calculated using the transfer relation on element $i$.

expressed on the left and on the right of each node $i$ of the structure (Fig. 3) by:

$$
\Delta^{n} S_{i, L}=\left\{\begin{array}{l}
\Delta^{n} Q \\
\Delta^{n} F
\end{array}\right\}_{i, L} \text { and } \Delta^{n} S_{i, R}=\left\{\begin{array}{l}
\Delta^{n} Q \\
\Delta^{n} F
\end{array}\right\}_{i, R} .
$$

Components of $\Delta^{n} S_{i, L}$ and $\Delta^{n} S_{i, R}$ are expressed in the local coordinate system of elements $i-1$ and $i$, respectively. $\Delta^{n} Q_{i, L}$ and $\Delta^{n} Q_{i, R}$ contain the generalised displacements of node $i$ whereas $\Delta^{n} F_{i, L}$ contains the forces which are transmitted by node $i$ on element $i-1$ and $\Delta^{n} F_{i, R}$ contains the forces which are exerted by node $i$ on element $i$. The ITMM allows increments of nodal displacements and internal forces to be determined during the cycle $n$.

\subsubsection{Node equilibrium and element changing}

Let ${ }^{n} B_{i}$ be the $3 \times 3$ direction cosine matrix which is used to transform vector coordinates from element $i-1$ to the element $i$ coordinate system. The vectors which contain the six generalised displacement increments on the left and on the right of node $i$ are linked by the matrix relation:

$$
\Delta^{n} Q_{i, R}={ }^{n} K_{i} \cdot \Delta^{n} Q_{i, L} \text { with }{ }^{n} K_{i}=\left(\begin{array}{cc}
{ }^{n} B_{i} & 0_{3 \times 3} \\
0_{3 \times 3} & { }^{n} B_{i}
\end{array}\right) .
$$

Furthermore, let $\Delta^{n} C L_{i}$ denote the vector of external force increments concentrated at node $i$, e.g. crown weight or wind forces. The mechanical equilibrium at node $i$ in the local coordinate system of element $i$ is written as:

$$
\Delta^{n} F_{i, R}=-{ }^{n} K_{i} \cdot \Delta^{n} F_{i, L}+\Delta^{n} C L_{i} .
$$

According to relations (10) and (11), we infer incremental state vector expression on the right of node $i$ in step with its expression on the left:

$$
\Delta^{n} S_{i, R}={ }^{n} P_{i} \cdot \Delta^{n} S_{i, L}+\Delta^{n} C_{i},
$$

with $\quad{ }^{n} P_{i}=\left(\begin{array}{cc}{ }^{n} K_{i} & 0_{6 \times 6} \\ 0_{6 \times 6} & -{ }^{n} K_{i}\end{array}\right) \quad$ and $\quad \Delta^{n} C_{i}=\left\{\begin{array}{c}0_{6} \\ \Delta^{n} C L_{i}\end{array}\right\}$. 
Table I. Summary of notations used to apply crown weight increments on tree stem.

\begin{tabular}{|c|c|c|}
\hline Notation $^{\mathrm{a}}$ & Unit & Definition \\
\hline${ }^{n} \mathrm{CWI}$ & $\mathrm{kg}$ & Global crown weight increment \\
\hline${ }^{n} C W T$ & $\mathrm{~kg}$ & Total weight of the crown \\
\hline${ }^{n} \mathrm{CWI} \mathrm{I}^{+}$ & $\mathrm{kg}$ & $\begin{array}{l}\text { Positive crown weight increment due to } \\
\text { growth }\end{array}$ \\
\hline${ }^{n} C W I^{-}$ & $\mathrm{kg}$ & $\begin{array}{c}\text { Negative crown weight increment due to } \\
\text { pruning }\end{array}$ \\
\hline${ }^{n} H$ & $\mathrm{~m}$ & Total tree height \\
\hline${ }^{n} \mathrm{CBH}$ & $\mathrm{m}$ & Crown base height \\
\hline${ }^{n} C Z=\left\lfloor{ }^{n} C B H,{ }^{n} H\right\rfloor$ & - & Current crown zone on the stem \\
\hline${ }^{n} P Z=\left[{ }^{n-1} C B H,{ }^{n} C B H\right]$ & - & Intermediate pruned zone \\
\hline${ }^{n} S Z=\left\lfloor 0,{ }^{n-1} C B H\right\rfloor$ & - & Stem zone without branches \\
\hline${ }^{n} \mathrm{CN}$ & - & $\begin{array}{l}\text { Number of stem nodes in the crown } \\
\text { (in }{ }^{n} C Z \text { ) }\end{array}$ \\
\hline$h \in\left[0,{ }^{n} H\right]$ & $\mathrm{m}$ & Height in the tree \\
\hline${ }^{n} \Delta W(h), h \in\left\lfloor 0,{ }^{n} H\right\rfloor$ & $\mathrm{kg} \cdot \mathrm{m}^{-1}$ & $\begin{array}{l}\text { Discontinuous distribution of crown wei- } \\
\text { ght increment }\end{array}$ \\
\hline${ }^{n} w(h), h \in{ }^{n} C Z$ & $\mathrm{~kg} \cdot \mathrm{m}^{-1}$ & $\begin{array}{l}\text { Distribution of crown weight increment } \\
\text { due to growth }\end{array}$ \\
\hline${ }^{n} w_{i}$ & $\mathrm{~kg} \quad \mathrm{I}$ & Discrete form of ${ }^{n} w(h)$ for nodes $i$ of ${ }^{n} C Z$ \\
\hline
\end{tabular}

a The $n$ exponent means that notations are used at cycle of growth $n$.

\subsubsection{Incremental transfer on element}

The matrix relation, which allows the incremental state vector on the left of node $i+1$ to be expressed according to the incremental state vector on the right of node $i$, is directly inferred from relation (8) and written as:

$$
\Delta^{n} S_{i+1, L}={ }^{n} T_{i} \cdot \Delta^{n} S_{i, R}+\Delta^{n} D_{i}+\Delta^{n} M_{i},
$$

where ${ }^{n} T_{i}, \Delta^{n} D_{i}$ and $\Delta^{n} M_{i}$ are given by ${ }^{n} T, \Delta^{n} D$ and $\Delta^{n} M$ expressions using self characteristics of element $i$.

\subsection{Incremental application of crown weight on stem structure}

Most of the static loads which are applied on a tree are due to the crown biomass increments resulting from addition and loss of branches. As the crown structure of simplified trees is not explicitly known, the weight increment distribution along the stem uses an empirical form, which can depend on the tree species. The notations used in order to detail the application of crown weight increment on tree stem are set out in Table I.

\subsubsection{Global balance of crown biomass increment at cycle $n$}

At cycle $n$, the global tree crown biomass increment is formally given by the difference between the current and the previous total weight of the crown: ${ }^{n} C W I={ }^{n} C W T-{ }^{n-1} C W T$. This weight increment also results from the balance between the positive increment of new vegetative biomass provided from growth and the negative increment ensuing from branch loss, so that: ${ }^{n} \mathrm{CWI}={ }^{n} \mathrm{CWI} I^{+}+{ }^{n} \mathrm{CWI}$. Loss of crown biomass is assumed to be mainly due to pruning of lowest branches. The stem can therefore be split into three zones:

${ }^{n} \mathrm{CZ}$ where the positive weight increment ${ }^{n} \mathrm{CWI}^{+}$is distributed; ${ }^{n} \mathrm{PZ}$ where the negative weight ${ }^{n} \mathrm{CWI}^{-}$due to loss of biomass is applied; ${ }^{n} S Z$, not directly loaded by the crown weight.

\subsubsection{General procedure for applying crown weight increment}

Distribution of crown weight increment along the stem is given at cycle $n$ by the discontinuous function ${ }^{n} \Delta W(h), h \in\left[0,{ }^{n} H\right]$ with regard to the following procedures:

- The negative increment of weight is calculated at height $h \in{ }^{n} P Z$ considering the local total biomass which has been removed between cycles $n-1$ and $n$. This local weight is explicitly determined by the cumulative formula:

$$
{ }^{n} \Delta W(h)=-\sum_{i=1}^{n-1}{ }^{i} \Delta W(h) .
$$

- The total loss of biomass due to pruning in the region ${ }^{n} P Z$ induces a reduction of weight which is given by: ${ }^{n} C W I^{-}=-\int_{n_{P Z}}\left(\sum_{i=1}^{n-1}{ }^{i} \Delta W(h)\right) d h$.

- The addition of weight due to the crown growth is given by ${ }^{n} C W I^{+}={ }^{n} C W I-{ }^{n} C W I^{-}$. This weight is distributed along the ${ }^{n} C Z$ zone using an analytical function ${ }^{n} w(h)$ which must fulfil the following condition:

$$
\int_{{ }^{n} C Z}^{n} w(h) \cdot d h={ }^{n} C W I^{+} .
$$

Note that ${ }^{n} \mathrm{CWI} I^{+} \geq{ }^{n} \mathrm{CWI}$.

Function ${ }^{n} w(h)$ is related to the crown biomass balance between two consecutive cycles of growth. This function is therefore associated with crown architecture and gives the spatial and temporal distribution of biomass, as well as the local vigour of growth. It is not easy to estimate ${ }^{n} w(h)$ with regard to the global crown shape only. This function has to be determined empirically for each species of interest. An alternative is to use architectural models, such as those developed by AMAP $[34,35]$, which allow the structural variability to be considered.

In practice, function ${ }^{n} w(h)$ is given as a discrete form and represents concentrated forces which are applied at stem nodes $i \in{ }^{n} C Z$. The resulting vector of nodal forces $\Delta^{n} C L_{i}=f\left({ }^{n} w_{i}\right)$ is thus incorporated into equation (11). Condition (14) becomes:

$$
\sum_{i \in{ }^{n} C Z}^{n} w_{i}={ }^{n} C W I^{+}
$$

Moreover, these concentrated forces define an approximation of real loads whereas branch topology and mass distribution in the crown are not given explicitly.

\subsection{Final ways to achieve the biomechanical analysis of tree stem}

\subsubsection{Particular procedures related to stem growth}

The numerical developments and subsequent simulations were mainly concerned by secondary biomechanical processes due to cell differentiation. For this reason, the influence of apical reorientation is not discussed here, even if this phenomenon can be strongly involved in tree stem movement and defects [18, 19, 44]. We will therefore 
consider that the new apical $G U$ is formed in the same direction of the bearing element.

The secondary straightening up is induced by a differential of maturation strains in the plane of flexion which is due to the presence of reaction wood. Stimuli of reaction wood formation are not wellknown. However, the secondary reorientation criterion can be given as a function of the stem leaning angle $[1,37,42,44,46]$. It can also be dependent on other variables, such as the stress (or strain) field for instance [11]. The geometrical criterion which was used in software AMAPpara [20] was chosen to control the negative-gravitropism in our model. A threshold angle $\alpha$ (with respect to the vertical direction) was used once to indicate the beginning of the stem straightening up. Moreover, a second threshold angle ${ }^{n} \beta$ was defined to control the straightening up of each $G U$. The reorientation process was simulated at each cycle $n$ according to the following algorithm: from the beginning of tree growth, we have ${ }^{n} \varsigma=0$ in the law (4) for every $G U$, i.e. the stem cannot react; during cycles of growth, if the leaning angle of one $G U$ at least is greater than $\alpha$ then the trunk starts to react; then for each $G U$, a reaction occurs $\left({ }^{n} \varsigma=1\right)$ if its leaning angle is greater than ${ }^{n} \beta$ and there is no reaction otherwise $\left({ }^{n} \varsigma=0\right)$. Note that the threshold angle ${ }^{n} \beta$, which is the same for every GU, can be defined for each cycle of growth, e.g. to be assimilated to the Gravitropic Set-point Angle defined by Digby and Firn [15]. Nevertheless, it will be assumed constant during growth in the results section: ${ }^{n} \beta=\beta$. Moreover, as mentioned above, intermediate values of ${ }^{n} \varsigma$ could be used in order to modulate the straightening up intensity. This parameter could be particularly given as a function of the leaning angle allowing the correlation between negative-gravitropism intensity and stem inclination to be taken into account $[42,44,46]$.

\subsubsection{Starting of the stem analysis method}

Each trunk is considered as a tapered cantilever. It is assumed to be perfectly embedded in the soil with a free extremity. The 12 associated boundary conditions $(B C)$ are given by:

$$
\left\{\begin{array}{c}
\Delta^{n} Q_{1, R}=0 \Rightarrow 6 \text { geometrical } B C \text { at fixed base } \\
\Delta^{n} F_{n+1, L}=0 \Rightarrow 6 \text { mechanical } B C \text { at free top. }
\end{array}\right.
$$

Six components of incremental state vectors at the right of node 1 and six components at the left of node $n+1$ are determined by these conditions. The Transfer Matrix Method consists of finding a linear system allowing the six unknown components of each vector to be solved. Going stepwise from the first till the last node, and using successively the transfer relations (13) and (12), allows this system to be established. After operating all matrix products and using $B C$ (16), it can take the following symbolic form:

$$
\left\{\begin{array}{c}
\Delta^{n} Q_{n+1, L} \\
0
\end{array}\right\}=\left(\begin{array}{cc}
{ }^{n} A_{Q Q} & { }^{n} A_{Q F} \\
{ }^{n} A_{F Q} & { }^{n} A_{F F}
\end{array}\right)\left\{\begin{array}{c}
0 \\
\Delta^{n} F_{1, R}
\end{array}\right\}+\left\{\begin{array}{c}
{ }^{n} B_{Q} \\
{ }^{n} B_{F}
\end{array}\right\} .
$$

This system allows the boundary state vectors to be completely known. In particular, the reaction forces at the fixed base are: $\Delta^{n} F_{1, R}=-{ }^{n} A_{F F}^{-1} \cdot{ }^{n} B_{F}$. From $\Delta^{n} S_{1, R}$, the stepwise procedure mentioned above allows the incremental state vector to be determined at all nodes of the structure. This process is the general method and leads a starting point for isostatic or hyperstatic problems. For a cantilever problem, it is easier to determine the reaction forces at the embedded base by expressing the global trunk equilibrium, i.e. calculating the resulting forces and moments due to external loading.

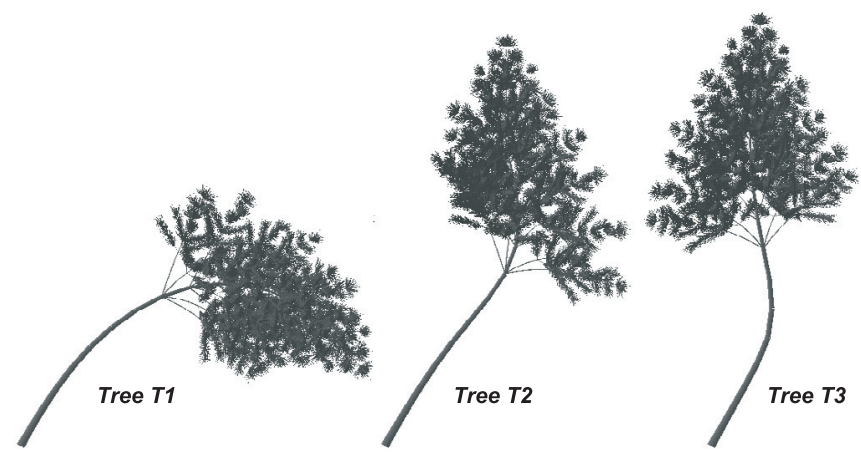

Figure 4. Reference trees have been computed with the software AMAPpara. Different final shapes were obtained using three strategies of straightening up. Tree $T l$ was performed without considering secondary straightening up, whereas trees $T 2$ and $T 3$ were submitted to maturation stresses inducing a stem negative-gravitropism. Results are shown at 20th cycle of growth.

\subsubsection{Outputs of the trunk biomechanical model}

The increments of nodal displacements are computed in a local coordinate system, crossing step by step beam elements of trunk with relations (12) and (13). After transforming these displacements in the global coordinate axes, the new stem shape, which corresponds to the new configuration ${ }^{n} C$, is determined. At each cycle, the location of reaction wood sectors in the current ring is saved. A post treatment allows cartographies of normal and reaction wood to be mapped at chosen positions along the stem. Furthermore, our model provides internal growth stresses which are linked with the current stem shape. Increment of stress is determined by computing generalised strain increment and using the material behaviour law of each wood layer, according to equation (5). The total field of stresses (Pa) depends on the growth and loading history according to the cumulative relation [19]:

$$
{ }^{n} \sigma_{c, i}=\sum_{d=d_{c, i}}^{n} \Delta^{d} \sigma_{c, i},
$$

where $d_{c, i}$ is the apparition cycle of the layer $c$ of beam element $i$.

\subsection{Evaluation of the simplified tree model}

\subsubsection{Description of reference trees}

Simulations of tree growth were performed with the software AMAPpara and its biomechanical function AMAPméca. The computed structure was taken as a reference in order to carry out a numerical evaluation of the ITMM biomechanical model. The advantage of this approach was to control both structural and mechanical parameters used for the calculations.

The reference tree corresponded to a model of Maritime pine (Pinus pinaster Ait.) which was already used by Fourcaud et al. [20]. Stem wood was considered to be homogeneous and isotropic. Young modulus $E$ was equal to $11 \mathrm{GPa}$ in all the rings and wood density $\rho$ was equal to $700 \mathrm{~kg} \cdot \mathrm{m}^{-3}$. The maturation strain model (4) was used with $a=-0.02 \%$ for normal wood and $b=0.1 \%$ for compression wood. These values were in good agreement with those measured by Alteyrac et al. [1] on a 17 year-old Maritime pine. The stem was considered to have an initial leaning angle of $30^{\circ}$. The computed distribution of crown biomass increments was recorded at each step of calculation. Three strategies of biomechanical behaviour were considered (Fig. 4). Tree $T 1$ was computed without a negative-gravitropic response, i.e. taking ${ }^{n} \varsigma=0$ in equation (4). This extreme case is of course not realistic but 


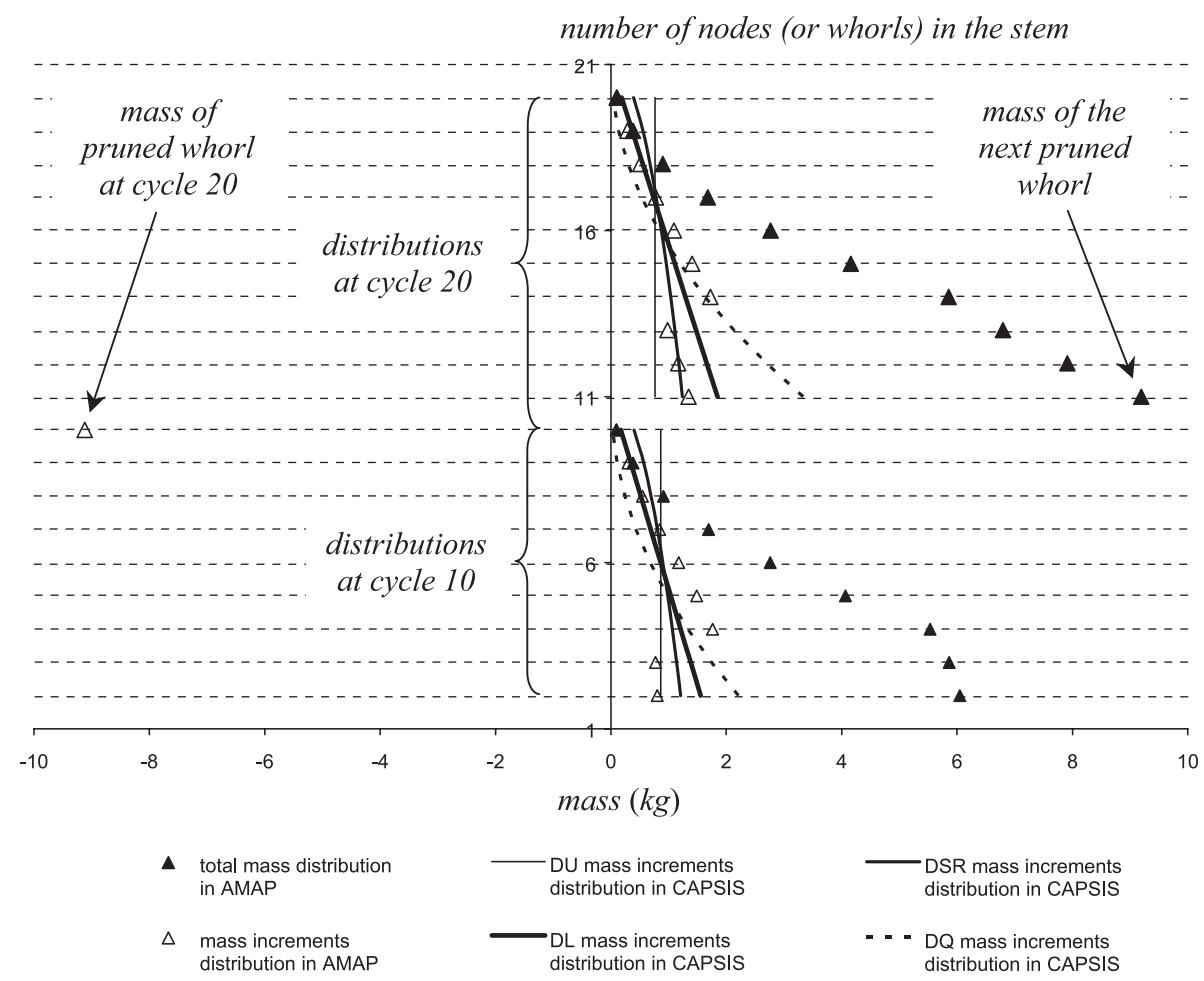

Figure 5. Distributions of crown biomass increments along the stem. $D U$ : discrete uniform distribution. $D L$ : discrete linear distribution. DSR: discrete square root distribution. $D Q$ : discrete quadratic distribution. it allows several models of crown mass distribution to be evaluated without any other influencing parameters. Secondary reorientation processes of trees $T 2$ and $T 3$ were controlled with threshold parameters $\left(\alpha_{2}, \beta_{2}\right)=\left(45^{\circ}, 0^{\circ}\right)$ and $\left(\alpha_{3}, \beta_{3}\right)=\left(35^{\circ}, 10^{\circ}\right)$ respectively, according to the straightening up strategy described in the previous section. In all the simulations, a new $G U$ was placed in the prolongation of the stem tip, i.e. primary reorientation was not considered.

\subsubsection{Loading functions for crown weight increments}

The ITMM was tested taking into consideration the biomass increments of the reference tree at each cycle of growth. Crown increment of mass and stem growth parameters ( $G U$ length and ring width) were taken from AMAPpara at each step. The crown biomass was given under a natural discrete form at each stem whorl. In the calculations, stem discretization was achieved so that generated nodes coincided with the whorl set and were numbered from the stem base to the tip. At cycle $n$, the number of stem nodes, including the embedded trunk base, is thus $n+1$ and the number of whorls bearing living branches is denoted ${ }^{n} \mathrm{CN}$. Crown weight increments were applied considering the following functions of weight distribution (Fig. 5):

- Single concentrated load (SC): the crown weight increment ${ }^{n} \mathrm{CWI}$ can be condensed as a single resultant force which occurs to the centre of crown mass increments. Positive and negative increments ${ }^{n} \mathrm{CWI}$ and ${ }^{n} \mathrm{CWI}^{-}$are not used in that case. It is assumed that this centre of mass is located at a node $N_{c}$ of the stem line which is given by AMAPpara. This hypothesis allows the load to be applied at a relative location with regard to the current deformed structure. This choice is necessary to compare ITMM results with AMAPméca calculations as the intermediate reference configurations are not identical (cf. Fig. 6 for instance). The loading due to crown weight is therefore determined by ${ }^{n} w_{c}={ }^{n} C W I$. This aggregated model has been considered because of its simplicity. This is indeed the first model which comes to mind for applications at the stand scale.

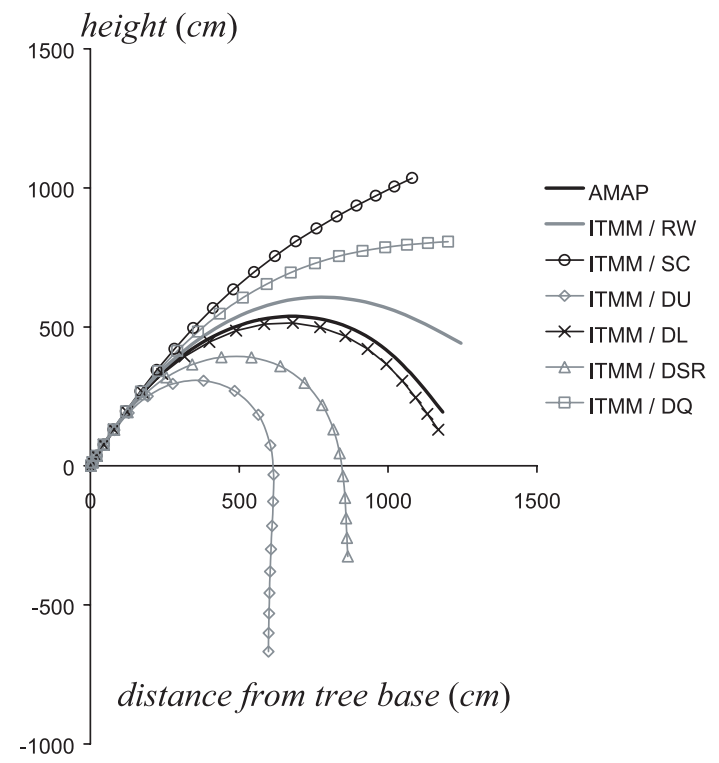

Figure 6. Stem shape resulting from 20 calculation steps of tree $T 1$ using different distribution modes of crown biomass increments in the ITMM procedure. $R W$ : real distribution per whorl. $S C$ : single concentrated load. $D U$ : discrete uniform distribution. $D L$ : discrete linear distribution. $D S R$ : discrete square root distribution. $D Q$ : discrete quadratic distribution.

- Real load distribution per whorl $(R W)$ : crown weight increment ${ }^{n} C W I$ is distributed in accordance with the real distribution of branch biomass which is explicitly given by AMAPpara for each stem whorl. This distribution includes negative values which are applied to the 
pruned whorls. Positive and negative increments ${ }^{n} \mathrm{CWI}^{+}$and ${ }^{n} \mathrm{CWI}^{-}$ are not directly used in this case. Nevertheless they can be deduced summing the contribution of each whorl.

- Discrete uniform load distribution $(D U)$ : the function of weight distribution is given by ${ }^{n} w_{i}={ }^{n} a_{0}$ for all nodes $i \in{ }^{n} C Z$. Condition (15) gives ${ }^{n} a_{0}=\frac{{ }^{n} C W I^{+}}{{ }^{n} C N-1}$.

- Discrete linear load distribution $(D L)$ : the function of weight distribution is given by ${ }^{n} w_{i}={ }^{n} a_{1} \cdot(n-i+1), i \in{ }^{n} C Z$. Condition (15) gives ${ }^{n} a_{1}=\frac{{ }^{n} C W I^{+}}{\sum_{k=1}^{{ }^{n} C N} k}$.

- Discrete square root load distribution $(D S R)$ : the function of weight distribution is given by ${ }^{n} w_{i}={ }^{n} a_{2} \cdot \sqrt{(n-i+1)}, i \in{ }^{n} C Z$, giving ${ }^{n} a_{2}=\frac{{ }^{n} C W I^{+}}{\sum_{k=1}^{n_{C N}} \sqrt{k}}$.

- Discrete quadratic load distribution $(D Q)$ : the function of weight distribution is given by ${ }^{n} w_{i}={ }^{n} a_{3} \cdot(n-i+1)^{2}, \quad i \in{ }^{n} C Z$, giving ${ }^{n} a_{3}=\frac{{ }^{n} C W I^{+}}{\sum_{k=1}^{n} k^{2}}$.

\section{RESULTS AND DISCUSSION}

\subsection{ITMM validation for a non-branching growing stem}

Numerical validation of our biomechanical model has been achieved by comparing the results of calculations obtained with AMAPméca for a reference growing stem without branches. Two cases were studied: firstly, loading due to the stem selfweight was only considered, and secondly, the negative-gravitropic response due to differential maturation strains was taken into account. In both cases, the computed displacement increments and cumulated growth stresses inside the stem were identical between the two models. The ITMM based biomechanical module has thus been correctly formulated and implemented, and it is therefore considered numerically validated. With regard to the finite element method, the computation method used does not involve differences in the calculated stem response.

\subsection{Evaluation of the simplified tree model}

The model presented in this paper and the module AMAPméca share the same biomechanical assumptions: the use of a homogeneous and isotropic material for stem wood, the description of stem internal structure using multi-layer 3D straight beam elements with circular cross-sections and concentric layers, the sinusoidal hoop distribution of maturation strains in the peripheral wood ring and the geometrical strategy of the negative-gravitropic response using two constant threshold angles, are common for the two models. Hence, as the ITMM provided the same results for non-branching stems as those obtained with the finite element method used in AMAPméca, the only difference between our biomechanical model and AMAPméca is the crown description. This description was simplified and aggregated here, while AMAPpara allows biomechanical calculations to be achieved using architectural tree structures. As shown above, our ITMM based model uses theoretical discrete distributions of concentrated loads allowing the application of crown weight on the tree stem.

\subsubsection{Model evaluation without secondary straightening up}

First results were obtained using AMAPpara reference tree $T 1$, i.e. without taking into consideration secondary straightening up (Fig. 6). At a given stage, stem shape results from a stepwise calculation during which increments of weight were applied progressively. However, as already explained by Fourcaud et al. [20], large resulting curvature is not due to stem flexibility but originates from a geometrical effect as the primary growth occurred at each cycle on a deformed shape. In the following discussions, it should be kept in mind that shape divergence which could be noted at a given stage resulted from cumulated differences during the stepwise calculation.

The ITMM result using loading $R W$ does not show as good accuracy as was expected. This can be explained by the fact that branch weights were resumed to resultant forces applied to stem whorls, neglecting residual moments which were also transmitted to the trunk. $S C$ loading led to a solution which was much straighter than the reference stem bending. Weight repartition along the stem was not taken into account and explains a part of this difference. Moreover, resultant moments were also neglected due to the hypothesis that the centres of mass increments were placed on the stem line. For large deflections, this assumption becomes not valid and the crown weight effect tends to be underestimated.

In view of the repartition of biomass increments (Fig. 5), it is clear that the best results (Fig. 6) were obtained with models fitting well the reference biomass at the top part of the crown. Loading model $D L$ led on the best approximation at 20 cycles for instance. On the contrary, $D U$ and $D S R$ gave non-satisfactory responses even if they fitted well the biomass distribution at the crown base. This statement is not surprising as beam stiffness decreases significantly from the base to the tip according to the stem taper. Moreover it is well-known that cantilever beam deflection is more sensitive to loads which are applied near the free extremity.

\subsubsection{Model evaluation with negative-gravitropic response}

Reference trees $T 2$ and $T 3$ (Fig. 4), which are associated with two different strategies of secondary straightening up, were used to evaluate the ITMM in more realistic situations. Trunk shape evolution shows that basal curvature is initiated at the first stages of growth. During this period, the stem fine extremity bends gradually under action of branch weight acting close to the tip. Primary lengthening, which is achieved in the prolongation of the stem, tends to amplify this deformation. During the following cycles, secondary growth increases beam stiffness, reducing significantly movements of the basal part of the 


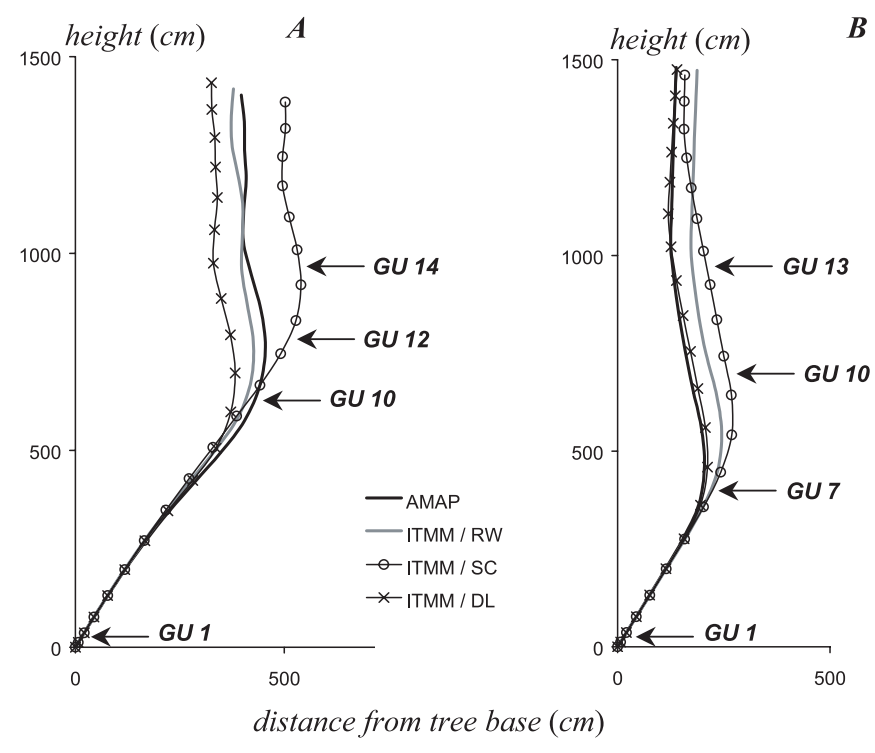

Figure 7. Stem shape resulting from 20 calculation steps of $A$ / tree $T 2$ and $B /$ tree $T 3$ using different distribution modes of crown biomass increments in the ITMM procedure. $R W$ : real distribution per whorl. $S C$ : single concentrated load. $D L$ : discrete linear distribution.

trunk. Inversion of stem curvature appears when the leaning angle of young terminal $G U s$ reaches the stem straightening up threshold $\alpha$. The tree apex then tends to return to a vertical position. Maximum stem curvatures, from which location thus depend generally on this angle $\alpha$, are situated at half stem height for tree $T 2$ and one third of trunk height for tree $T 3$.

Only crown loading models $S C, R W$ and $D L$ were applied in order to test ITMM, as other distributions were shown not to be satisfying. Fairly good agreements can be seen in the lower two thirds of the trunk for both strategies T2 and T3 (Fig. 7). In each case, the three ITMM calculations reach a maximum curvature at the same location on the trunk, except for $S C$ applied on tree $T 2$. Radii of curvature are also very close in each test. Nevertheless, results are globally better for tree $T 3$ for which the model $D L$ is very good. These responses can be explained by looking at the previous results relative to tree $T 1$. Models $S C$ and $R W$, underestimating the real bending, reach the threshold of straightening up later than the reference tree, whereas model $D L$, which overestimates this bending, starts to react earlier. Consequently, delay or advance of the reaction process involves divergence of mechanical response. It can also be noticed that the sooner stem verticality is reached the less visible the differences between models. Stem closeness from the vertical position indeed limits bending moments which are generally responsible for the recorded shape differences.

Model evaluation was also concerned with the calculation of longitudinal growth stresses $(L G S)$. These stresses were computed for both trees $T 2$ and $T 3$ using the ITMM and considering crown loading models $S C$ and $D L$. Results were compared with those obtained by AMAPméca. Good agreements were found concerning the $L G S$ general radial profiles in the part of the stem which is situated below the straightening up zone, i.e. under the maximum curvature (Fig. 8). Nevertheless, maximum tensile $L G S$ at the stem base is not always located at the same distance of the pith and their intensity is significantly different for tree $T 3$. These gaps can be explained by the delay or advance of the reaction processes. Differences of stress intensity can also result from the different positions of the upper part of the stem (Fig. 7) which involve different bending moments due to the crown weight. Basal growth units show more $L G S$ divergence as they have a longer growth history and thus support more stress increments. For the same reason, differences can also be visible in the more internal growth rings. $L G S$ profiles are not comparable in cross-sections closed to the zone of maximum curvature. No more accordance of $L G S$ distribution is observed in cross sections in the upper part of the stem. Leaving radial distribution out of account and considering only the maximum and minimum $L G S$ values, it is interesting to notice the strong accordance of the results for tree $T 2$ (Fig. 9) as well as in the first half of tree T3.

\section{CONCLUSION}

The ITMM is a simple and efficient method to simulate the biomechanical behaviour of growing trees. Nevertheless, the use of numerical methods at the forest stand scale, i.e. on a large number of trees, necessitates representing the influence of the crown weight using an aggregated form. It was shown that this simplification is not trivial. At each cycle of growth, location of newly appeared biomass as well as position of lost material into the crown is highly species dependent. Furthermore, the stem negative-gravitropism can significantly modify the validity of load application models, giving more or less acceptable results in terms of stem shape or inner $L G S$. Quality of calculation outputs depends on criteria that are used for applications at the stand scale. In order to characterise timber quality in Aquitaine maritime pine forests for instance, foresters often look at the stem base leaning and intensity of the basal curvature which provide good indicators of pith eccentricity and the amount of compression wood. On the other hand, growth stresses in broadleaf trees are often considered as the most important factor responsible for log end-splitting or critical sawn board distortions. Evaluation of models with regard to the expected output for specific applications is therefore of great interest. It has been shown that severe simplifications of crown loading can provide relatively good agreements in terms of both shape and $L G S$ distribution, at least in the valuable part of the trunk. Architectural models allow typical tree structures to be generated. These virtual trees would be useful to determine more adapted models of biomass repartition, to be used on simplified trees at the stand scale for a given purpose.

The objective of future studies will be to perform numerical analyses of stem shape variability and wood quality, taking into consideration environmental constraints, i.e. spatial competition or the silvicultural scenario used. For this purpose, the ITMM will be coupled with spatial competition models developed in CAPSIS.

Acknowledgements: This work was carried out during a $\mathrm{PhD}$ thesis which was funded by INRA-FMN and Région Aquitaine. We wish to thank Alexia Stokes and Neal Harries for their corrections and language review. We also thank two anonymous reviewers for their comments and suggestions. 
Tree $T 2$
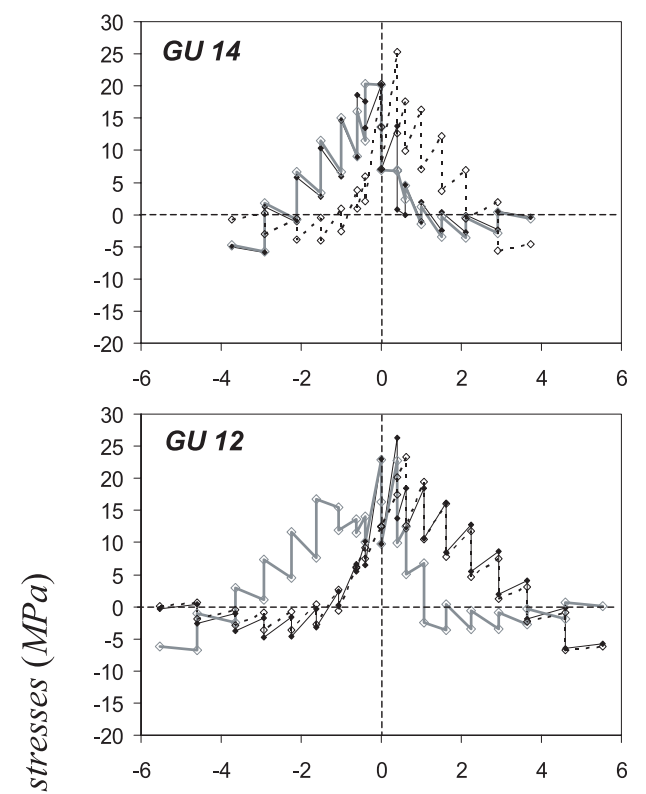

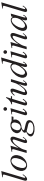
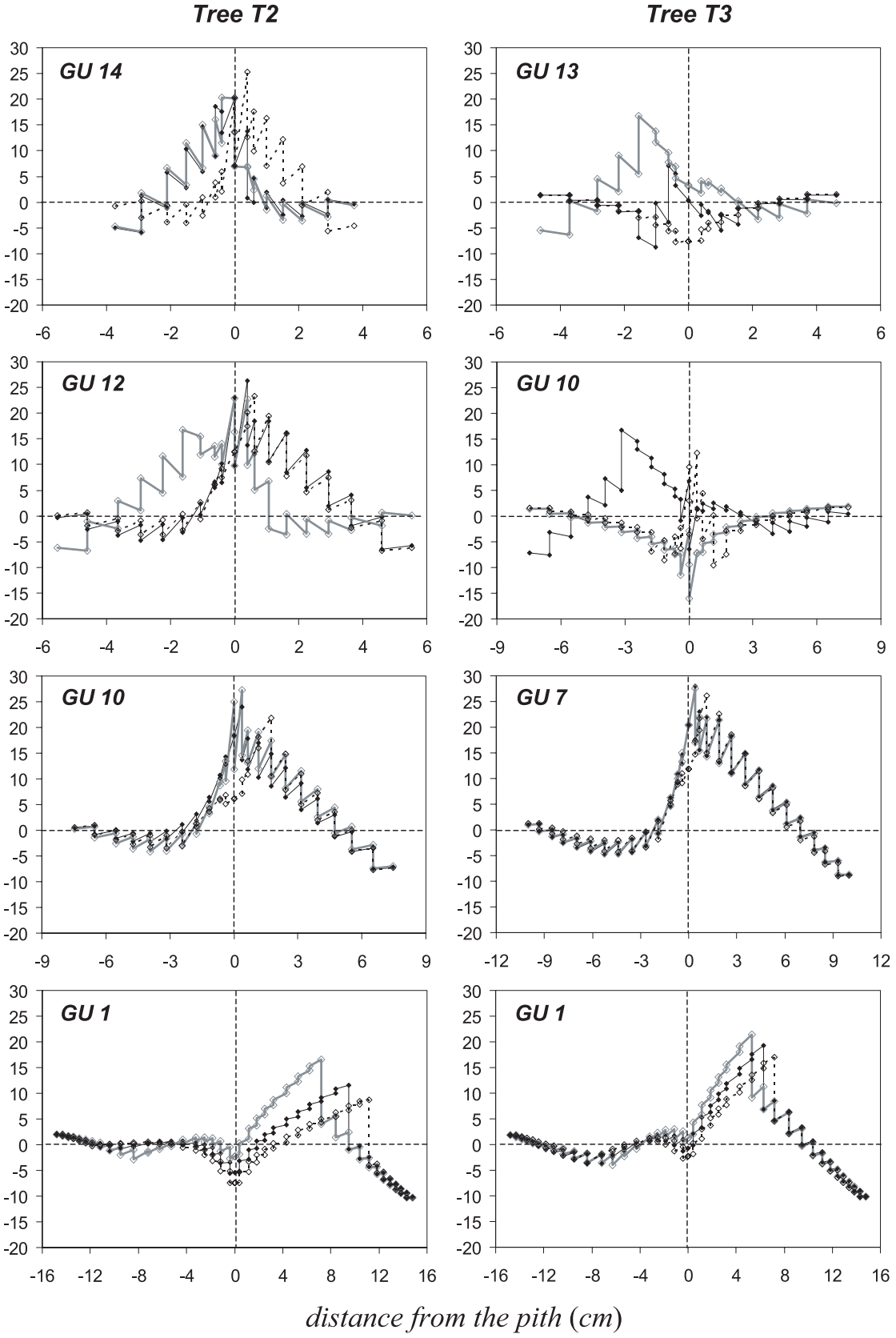

$\rightarrow$ AMAP $\rightarrow$ ITMM/DL $\rightarrow-$ ITMM/SC

Figure 8. Radial distribution of longitudinal growth stresses in the plane of leaning, resulting from 20 steps of calculation and using two distribution modes of crown biomass increments in the ITMM procedure. $S C$ : single concentrated load. $D L$ : discrete linear distribution. Location of growth units along the stem of trees $T 2$ and $T 3$ is shown in Figure 7.

\section{APPENDIX: BASICS OF THE TRANSFER MATRIX METHOD OF 3D STRAIGHT BEAMS}

A full description of the strength of materials, including elasticity and beam theories, is given by Timoshenko [38]. The Transfer Matrix Method is described by Tuma [40] and its formulation with 3D straight beams is detailed by Ancelin [2].

\section{A1. Kinematics}

3D straight beam is characterised by associated vectors of generalised displacements $\left(u, v, w, \omega_{x}, \omega_{y}, \omega_{z}\right)$ and generalised internal forces $\left(N_{x}, V_{v}, V_{z}, M_{x}, M_{y}, M_{z}\right)$, according to the beam local reference axes $\stackrel{\vec{x}}{x}, \vec{y}, \vec{z}$ (Fig. 10). Euler-Bernoulli assumptions in beam theory give how a beam cross section rotates. Defining normals as the lines perpendicular to the beam's 


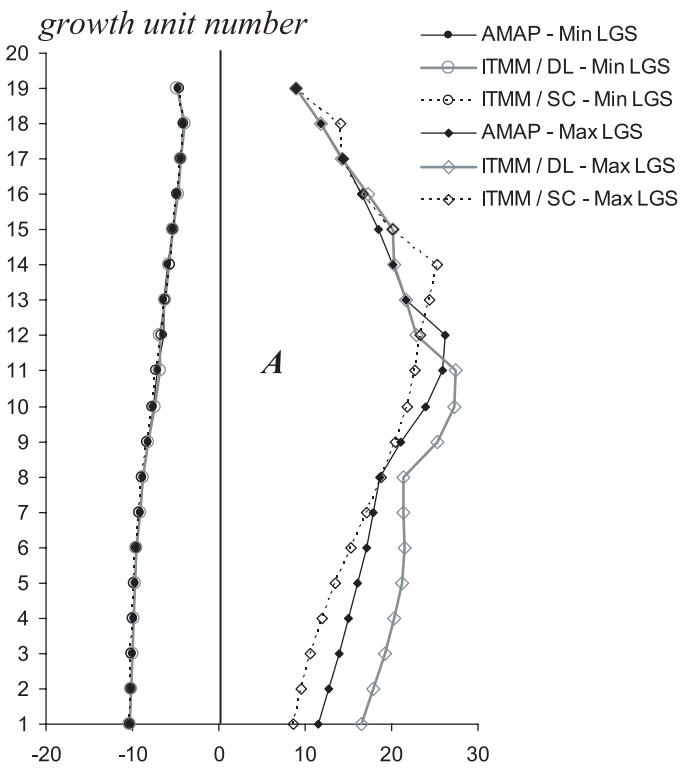

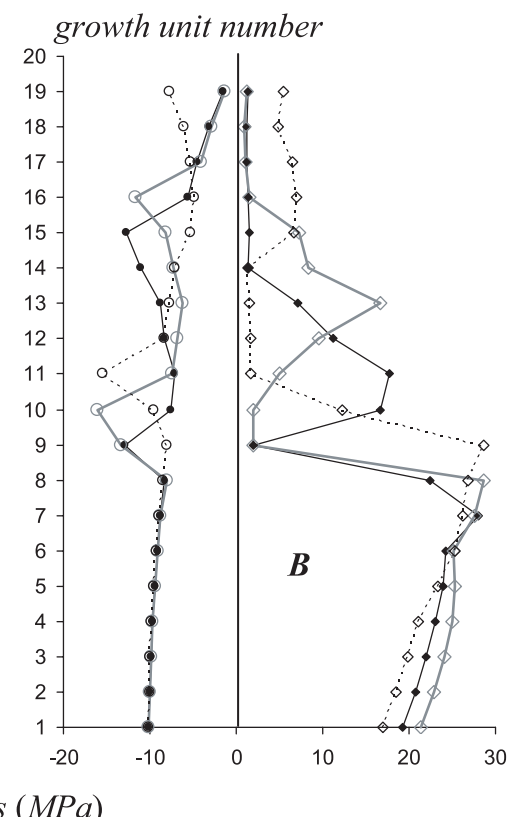

Figure 9. Maximal and minimal longitudinal growth stresses $(L G S)$ along the stem for $A$ / tree $T 2$ and $B /$ tree $T 3$. Results obtained from 20 steps of calculation using two distribution modes of crown biomass increments in the ITMM procedure. SC: single concentrated load. $D L$ : discrete linear distribution.

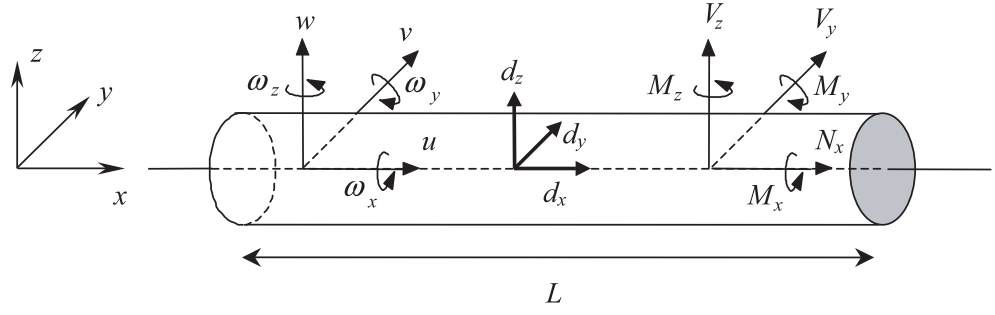

Figure 10. Generalised displacements and internal forces in a 3D straight beam subjected to distributed loads. $\vec{x}, \vec{y}, \vec{z}$ are the local reference axes of the beam. $u, v, w$ are the positive translations of cross-section centre $(\mathrm{m}) ; \omega_{x}, \omega_{y}, \omega_{z}$ are the positive rotations of cross-section normal (radians). $d_{x}$, $d_{y}, d_{z}$ are the distributed loads $\left(\mathrm{N} \cdot \mathrm{m}^{-1}\right)$, and are positive in the local directions. $N_{x}$ (normal force, $\mathrm{N}$ ), $V_{y}, V_{z}$ (shear forces, N), $M_{x}$ (torsion moment, N.m), $M_{y}, M_{z}$ (bending moments, N.m) are the positive internal forces. neutral fibre, assumptions stipulate these normals remain straight, unstretched and normal.

\section{A2. Equilibrium}

Equilibrium equations of the Static Fundamental Principle define generalised internal forces according to uniformly distributed loads $d_{x}, d_{y}, d_{z}$ :

$$
\begin{gathered}
\frac{d N_{x}}{d x}=-d_{x} ; \frac{d V_{y}}{d x}=-d_{y} ; \quad \frac{d V_{z}}{d x}=-d_{z} ; \\
\frac{d M_{x}}{d x}=0 ; \frac{d M_{y}}{d x}=V_{z} ; \frac{d M_{z}}{d x}=-V_{y} .
\end{gathered}
$$

By using strain compatibility of Bernoulli's model, we obtain the equations which define generalised displacements according to generalised internal forces:

$$
\begin{gathered}
\frac{d u}{d x}=\frac{N_{x}}{E . A} ; \frac{d v}{d x}=\omega_{y} ; \frac{d w}{d x}=-\omega_{y} ; \\
\frac{d \omega_{x}}{d x}=\frac{M_{x}}{G . J} ; \frac{d \omega_{y}}{d x}=\frac{M_{y}}{E . I_{y}} ; \frac{d \omega_{z}}{d x}=\frac{M_{z}}{E . I_{z}},
\end{gathered}
$$

where $E$ is the Young's modulus and $G=E / 2(1+v)$ the shear modulus, $v$ being Poisson's coefficient. The moments of inertia of the cross-section are defined with respect to the beam local reference axes $\vec{y}, \vec{z}, \vec{x}$ by:

$I_{y}=\int z^{2} \cdot d A ; \quad I_{z}=\int y^{2} \cdot d A ; \quad J=\int\left(y^{2}+z^{2}\right) \cdot d A$, where $A$ is the beam cross-section area.

\section{A3. Transfer matrix method}

We consider a 3D beam of length $L$ with a circular crosssection. Moments of inertia of this cross-section verify $I_{y}=I_{z}=I$ and $J=2 I$. By integrating equations (A.1) and (A.2) between extremity nodes $x=0$ and $x=L$, we obtain generalised internal forces and generalised displacements at the beam nodes. State vectors $S_{O}$ at the beam origin and $S_{E}$ at the beam extremity are defined by:

$$
\left\{\begin{array}{c}
S_{O}=\left\langle\begin{array}{llllll}
u_{O} & v_{O} & w_{O} & \omega_{x O} & \omega_{y O} & \omega_{z O} \mid-N_{x O}-V_{y O}-V_{z O}-M_{x O}-M_{y O}-M_{z O}
\end{array}\right\rangle^{t} \\
S_{E}=\left\langle\begin{array}{llllllllllll}
u_{E} & v_{E} & w_{E} & \omega_{x E} & \omega_{y E} & \omega_{z E} \mid N_{x E} & V_{y E} & V_{z E} & M_{x E} & M_{y E} & M_{z E}
\end{array}\right\rangle^{t} .
\end{array}\right.
$$

The transfer relation links $S_{E}$ to $S_{O}$ and is written [2]:

$$
S_{E}=T \cdot S_{O}+D
$$

where $T$ is the transfer matrix of the beam and $D$ is the state vector of distributed loads. $T$ and $D$ matrices are given by:

$$
T=\left(\begin{array}{ll}
T_{11} & T_{12} \\
T_{21} & T_{22}
\end{array}\right) ; \quad D=\left(\begin{array}{l}
D_{1} \\
D_{2}
\end{array}\right)
$$


where:

$$
\begin{aligned}
T_{11} & =\left(\begin{array}{cccccc}
1 & 0 & 0 & 0 & 0 & 0 \\
0 & 1 & 0 & 0 & 0 & L \\
0 & 0 & 1 & 0 & -L & 0 \\
0 & 0 & 0 & 1 & 0 & 0 \\
0 & 0 & 0 & 0 & 1 & 0 \\
0 & 0 & 0 & 0 & 0 & 1
\end{array}\right) ; \\
T_{12} & =\left(\begin{array}{cccccc}
\frac{-L}{E A} & 0 & 0 & 0 & 0 & 0 \\
0 & \frac{L^{3}}{6 E I} & 0 & 0 & 0 & \frac{-L^{2}}{2 E I} \\
0 & 0 & \frac{L^{3}}{6 E I} & 0 & \frac{L^{2}}{2 E I} & 0 \\
0 & 0 & 0 & \frac{-L}{G J} & 0 & 0 \\
0 & 0 & \frac{-L^{2}}{2 E I} & 0 & \frac{-L}{E I} & 0 \\
0 & \frac{L^{2}}{2 E I} & 0 & 0 & 0 & \frac{-L}{E I}
\end{array}\right) ;
\end{aligned}
$$$$
T_{21}=\left(\begin{array}{cccccc}
0 & 0 & 0 & 0 & 0 & 0 \\
0 & 0 & 0 & 0 & 0 & 0 \\
0 & 0 & 0 & 0 & 0 & 0 \\
0 & 0 & 0 & 0 & 0 & 0 \\
0 & 0 & 0 & 0 & 0 & 0 \\
0 & 0 & 0 & 0 & 0 & 0
\end{array}\right) ;
$$$$
T_{22}=\left(\begin{array}{cccccc}
-1 & 0 & 0 & 0 & 0 & 0 \\
0 & -1 & 0 & 0 & 0 & 0 \\
0 & 0 & -1 & 0 & 0 & 0 \\
0 & 0 & 0 & -1 & 0 & 0 \\
0 & 0 & -L & 0 & -1 & 0 \\
0 & L & 0 & 0 & 0 & -1
\end{array}\right) ;
$$$$
D_{1}=\left\langle\frac{-L^{2} d_{x}}{2 E A} \frac{L^{4} d_{y}}{24 E I} \quad \frac{L^{4} d_{z}}{24 E I} \quad 0 \quad \frac{-L^{3} d_{z}}{6 E I} \quad \frac{L^{3} d_{y}}{6 E I}\right\rangle^{t}
$$

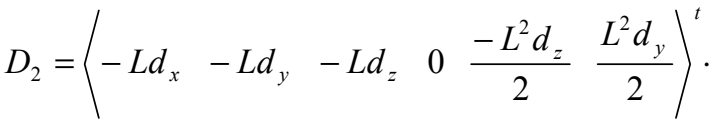

\section{REFERENCES}

[1] Alteyrac J., Fourcaud T., Castera P., Stokes A., Analysis and simulation of stem righting movements in Maritime pine (Pinus pinaster Ait.), in: Proc. Connection between silviculture and wood quality through modelling approaches and simulation software, Third Workshop of IUFRO WP S5.01-04, La Londe-Les-Maures, France, September 5-12, 1999, pp. 105-112.

[2] Ancelin P., Modélisation du comportement biomécanique de l'arbre dans son environnement forestier. Application au pin maritime, Thèse de Doctorat, Université de Bordeaux I, France, $\mathrm{N}^{\circ} 2343,2001$, $182 \mathrm{p}$.
[3] Archer R.R., Growth Stresses and Strains in Trees, Springer Verlag Series in Wood Science, Timell T.E. (Ed.), 1986.

[4] Biging G.S., Dobbertin M., Evaluation of competition indices in individual tree growth models, Forest Sci. 41 (1995) 360-377.

[5] Boyd J.D., Compression wood: force generation and functional mechanics, New Zeal. J. Forest Sci. 3 (1973) 240-258.

[6] Cannell M.G.R., Morgan J., Murray M.B., Diameters and dry weights of tree shoots: effect of Young's modulus, taper, deflection and angle, Tree Physiol. 4 (1988) 219-231.

[7] Castéra P., Morlier V., Growth patterns and bending mechanics of branches, Trees-Struct. Funct. 5 (1991) 232-238.

[8] Cescatti A., Modelling the radiative transfer in discontinuous canopies of asymmetric crowns. I. Model structure and algorithms, Ecol. Model. 101 (1997) 263-274.

[9] Cluzeau C., Dupouey J.L., Courbaud B., Polyhedral representation of crown shape. A geometric tool for growth modelling, Ann. Sci. Forest. 52 (1995) 297-306.

[10] Coligny (de) F., Ancelin P., Cornu G., Courbaud B., Dreyfus P., Goreaud F., Gourlet-Fleury S., Meredieu C., Saint-André L., CAPSIS: Computer-Aided Projection for Strategies in Silviculture: advantages of a shared forest-modelling platform, in: Amaro A., Reed D., Soares P. (Eds.), Modelling Forest Systems, CABI Publishing, Wallingford, UK, 2003, pp. 319-323.

[11] Constant T., Ancelin P., Fourcaud T., Fournier M., Jaeger M., The French project SICRODEF: a chain of simulators from the tree growth to the distortion of boards due to the release of growth stresses during sawing: First results, in: Proc. Connection between silviculture and wood quality through modelling approaches and simulation software, Third Workshop of IUFRO WP S5.01-04, La Londe-Les-Maures, France, September 5-12, 1999, pp. 377-386.

[12] Courbaud B., Goreaud F., Dreyfus P., Bonnet F.R., Evaluating thinning strategies using a Tree Distance Dependent Growth Model: some examples based on the CAPSIS software "Uneven-Aged Spruce Forests" module, For. Ecol. Manag. 145 (2001) 15-28.

[13] Courbaud B., Coligny (de) F., Cordonnier T., Simulating radiation distribution in a heterogeneous Norway spruce forest on a slope. Agric. For. Meteorol. 116 (2003) 1-18.

[14] Courbet F., Houllier F., Modelling the profile and internal structure of tree stem. Application to Cedrus atlantica Manetti, Ann. For. Sci. 59 (2002) 63-80

[15] Digby J., Firn R.D., The gravitropic set-point angle (GSA): the identification of an important developmental controlled variable governing plant architecture, Plant Cell Environ. 59 (1995) 1434-1440.

[16] Dreyfus P., Bonnet F.R., CAPSIS (Computer-Aided Projection of Strategies in Silviculture): an interactive simulation and comparison tool for tree and stand growth, silvicultural treatments and timber assortment, in: Proc. Connection between silviculture and wood quality through modelling approaches and simulation software. IUFRO WP S5.01-04 second workshop, Berg-en-Dal, Kruger National Park, South Africa, August 26-31, 1996, pp. 57-58.

[17] Ford E.D., Sorrensen K.A., Theory and models of inter-plant competition as a spatial process, in: DeAngelis D.L., Gross L. (Eds.), Populations, Communities and Ecosystems, Individual-Based Models and Approaches in Ecology, Chapman \& Hall, New York, 1992, pp. 363-407.

[18] Fourcaud T., Défauts de forme et structure interne du Pin maritime, in: Actes du $5^{\mathrm{e}}$ colloque "De la forêt cultivée à l'industrie de demain - Propriétés et usages du Pin maritime", ARBORA, 2-3 décembre, Bordeaux, France, 1999, pp. 77-84.

[19] Fourcaud T., Lac P., Numerical modelling of shape regulation and growth stresses in trees. Part I: an incremental static finite element formulation, Trees-Struct. Funct. 17 (2003) 23-30. 
[20] Fourcaud T., Blaise F., Lac P., Castéra P., Reffye (de) P., Numerical modelling of shape regulation and growth stresses in trees. Part II: implementation in the AMAPPARA software and simulation of tree growth, Trees-Struct. Funct. 17 (2003) 31-39.

[21] Fournier M., Bordonne P.A., Guitard D., Okuyama T., Growth stress patterns in tree stems - A model assuming evolution with the tree age of maturation strains, Wood Sci. Technol. 24 (1990) 131-142.

[22] Fournier M., Baillères H., Chanson B., Tree biomechanics: growth, cumulative prestresses, and reorientations, Biomimetics 2 (1994) 229-251.

[23] Gardiner B., Peltola H, Kellomäki S., Comparison of two models for predicting the critical wind speeds required to damage coniferous trees, Ecol. Model. 129 (2000) 1-23.

[24] Gillis P.P., Theory of growth stresses, Holzforschung 27 (1973) 197-207.

[25] Hallé F., Oldemann R.A.A., Tomlinson P.B., Tropical trees and forests, Springer Verlag, Berlin, 1978.

[26] Kubler H., Growth Stresses in Trees and Related Wood Properties, For. Abs. 48 (1987) 130-189.

[27] Lemoine B., Growth and yield of maritime pine (Pinus pinaster Ait.): the average dominant tree of the stand, Ann. Sci. Forest. 48 (1991) 593-611.

[28] Milne R., Blackburn P., The elasticity and vertical distribution of stress within stems of Picea sitchensis, Tree Physiol. 5 (1989) 195205.

[29] Morgan J., Cannell M.G.R., Structural analysis of tree trunks and branches: tapered cantilever beams subject to large deflections under complex loadings, Tree Physiol. 3 (1987) 365-374.

[30] Morgan J., Cannell M.G.R., Support cost of different branch designs: effects of position, number, angle and deflection of laterals, Tree Physiol. 4 (1988) 303-313.

[31] Morgan J., Cannell M.G.R., Shape of tree stems - a re-examination of the uniform stress hypothesis, Tree Physiol. 14 (1994) 49-62.

[32] Peltola H., Nykänen M.L., Kellomäki S., Model computations on the critical combination of snow loading and wind speed for snow damage of Scots pine, Norway spruce and Birch sp. at stand edge, For. Ecol. Manage. 95 (1997) 229-241.
[33] Pukkala T., Methods to describe the competition process in a tree stand, Scand. J. For. Res. 4 (1989) 187-202.

[34] Reffye (de) P., Fourcaud T., Blaise F., Barthélémy D., Houllier F., A functional model of tree growth and tree architecture, Silva Fenn. 31 (1997) 297-311.

[35] Reffye (de) P., Houllier F., Blaise F., Fourcaud T., Essai sur les relations entre l'architecture d'un arbre et la grosseur de ses axes végétatifs, in: Modélisation et Simulation de l'architecture des végétaux, INRA Ed., Sciences Update, 1997, pp. 255-423.

[36] Sorrensen-Cothern K.A., Ford E.D., Sprugel D.G., A model of competition incorporating plasticity through modular foliage and crown development, Ecol. Monogr. 63 (1993) 277-304.

[37] Timell T.E., Compression Wood in Gymnosperms, Springer Series in Wood Science, Springer-Verlag, Berlin, 3 vol., 1986.

[38] Timoshenko S.P., Résistance des matériaux, Dunod ed., Paris (translated from: Strength of materials, D. Van Nostrand Company Inc., Princeton), 1968

[39] Tomé M., Burkhart H.E., Distance-dependent competition measures for predicting growth of individual trees, For. Sci. 35 (1989) 816831 .

[40] Tuma J.J., Structural analysis, McGraw-Hill, 1968.

[41] West P.W., Jackett D.R., Sykes S.J., Stresses in, and the shape of, tree stems in forest monoculture, J. Theor. Biol. 140 (1989) 327-343.

[42] Wilson B.F., Gartner B., Lean in red alder (Alnus rubra): growth stress, tension wood and righting response, Can. J. For. Res. 26 (1996) 1951-1956.

[43] Yamamoto H., Okuyama T., Analysis of the generation process of growth stresses in cell walls, Mokuzai Gakkaishi 34 (1988) 788793.

[44] Yamamoto H., Yoshida M., Okuyama T., Growth stress controls negative gravitropism in woody plant stems, Planta 216 (2002) 280 292.

[45] Yang J.L., Waugh G., Growth stress, its measurements and effects, Austral. Forestry 62 (2001) 127-135.

[46] Yoshida M., Okuda T., Okuyama T., Tension wood and growth stress induced by artificial inclination in Liriodendron tulipifera Linn. and Prunus spachiana Kitamura f. ascendens Kitamura, Ann. For. Sci. 57 (2000) 739-746. 